\title{
Selective effects of disturbance on populations of sea anemones from northern Baja California, Mexico
}

\author{
Jesús Pineda*, Anamaría Escofet \\ Centro de Investigación Científica y de Educación Superior de Ensenada, Av. Espinoza 447, Ensenada, Baja California, México
}

\begin{abstract}
Effects of desiccation and sand burial on the survival and behavior of intertidal sea anemones Anthopleura elegantissima from northern Baja California were studied experimentally by comparing: (1) clonal and solitary forms (probably a pair of sibling species) (Francis 1979); (2) aggregated and 'wandering' (isolated module) configurations of the clonal form; and (3) large and small individuals of the solitary form. We tested the hypothesis that mobility and size are important attributes to avoid desiccation and sand burial. The hypothesis partially explains and predicts the differential distribution of the above categories in habitats with different disturbance regimes. Wandering modules were more susceptible to desiccation than were the aggregated clonal anemones, and wandering anemones moved more in response to desiccation than did aggregated ones. Both wandering and aggregated anemones showed little mobility when faced with sand burial. Small solitary anemones were more susceptible to desiccation than were large ones. They increased their mobility when confronted with this disturbance, larger specimens did not. Small solitaries reacted to sand burial by increasing their mobility; large ones did not increase their mobility but avoided burial by elongating their column. Mobility and size were important attributes of solitary anemones for avoiding sand burial. The clonal form is much less mobile and the individuals tend to be smaller, perhaps because of the aggregated configuration. While the aggregated strategy may reduce the effects of desiccation, the accompanying low mobility may reduce the opportunity to avoid other disturbances. The solitary form is better adapted to sand-influenced habitats. The clonal form is well protected from desiccation but only as an aggregated configuration.
\end{abstract}

\section{INTRODUCTION}

Disturbances are events of biotic or abiotic origin that destroy biomass (Dethier 1984), and are important factors in structuring hard-bottom marine populations (Paine 1979, Suchanek 1981) and communities (Dayton 1971, Connell 1978, Sousa 1979. Paine \& Levin 1981. Taylor \& Littler 1982, Dethier 1984). That distinct attributes of species or size classes can result in differential susceptibility to disturbance events implies that these, in turn, may create community or population patterns. Sessile species are at the mercy of disturbances that mobile species can avoid. However mobility as a strategy to avoid disturbance has received little attention in marine benthic communities (Sousa 1985).

\footnotetext{
- Present address: A-008 Scripps Institution of Oceanography, University of California, San Diego, La Jolla, California 92093, USA
}

Differential susceptibility among species or within populations may depend on size; some larger invertebrates in exposed sites, for example, are more susceptible than small ones to wave action (Denny et al. 1985). Conversely, small sea anemones are more susceptible to desiccation (Ottaway 1973, 1979) and predation (Anett \& Pierotti 1984). Other differences in susceptibility are related to the degree of aggregation; colonial organisms are generally more susceptible to desiccation, sand burial and instability of the substrate than are solitary species (Jackson 1977). Thus, behavioral, morphological and physiological characteristics could be the basis for strategies resulting in differential abundance of guilds, species or population size classes in disturbed habitats.

Anthopleura elegantissima (Brandt, 1835) (Anthozoa; Actinaria) is an intertidal anemone common between Alaska and Baja California (Hand 1955, Francis 1979). It occurs in clonal and solitary forms. The 
clonal form reproduces sexually and asexually, is relatively small, and lives high in the intertidal (Francis 1979). It occurs as isolated individuals (here termed wandering) or as large clonal aggregations, each ultimately developed by longitudinal fission (Hand 1955) from a single wandering anemone (Francis 1973a). Wandering individuals are sexually produced recruits or disaggregated asexually produced individuals. Being gregarious and covered with sedimentary particles attached to adhesive verrucae protects them from desiccation (Roberts 1941, Hart \& Crowe 1977, Francis 1979). The solitary form reproduces only sexually, is larger, and lives lower in the intertidal and in more protected locations than does the clonal form (Hand 1955). Large solitaries also occur in wave-swept habitats, growing next to their congener Anthopleura xanthogrammica (J. P. unpubl.).

The relationships between the clonal and the solitary forms are not clear (Carefoot 1977. Francis 1979, Sebens 1983), but some proposals have been put forward. Sebens (1979) created a model that predicts a relationship between the level of aggregation and the individual's size according to prey abundance and size, and suggested (Sebens 1980) that if the clonal and the solitary forms are the same species, large solitaries may develop from wandering anemones by continuous feeding. Francis (1979) proposed that differences in the aggregation and size of individuals may be related to competition, predation, and resistance to desiccation. Waters (1973) suggested that the occurrence of aggregations is related to avoidance of predation by nudibranchs. The 2 forms differ phenotypically in the same localities and have different geographic distributions. The clonal form is found from Alaska to Baja California, but solitaries are not found north of Bodega Head, California (Francis 1979). This led Francis (1979) to suggest that these forms are actually a sibling species pair. However, Smith \& Potts (1987) found that the solitary and clonal forms were electrophoretically indistinguishable.

Desiccation has been shown to kill anemones in natural conditions (Dayton 1971 for Anthopleura elegantissima, Ottaway 1979 for Actinia tenebrosa). In late winter and early spring of 1985, 1986 and 1987 we found (J. P. pers. obs.) dry dead wandering clonal anemones, presumedly killed by desiccation. Dayton (1971) suggested that the distribution of clonal $A$. elegantissima seemed partially limited by desiccation, and that 'the only hypothesis forthcoming' to explain certain results was that anemones reacted to desiccation by increasing their movement until encountering a refuge. Sebens (1983) found that the same species moved more in spring and summer than in fall and winter possibly because desiccation was harsher in the warmer seasons. Ottaway (1978) found that $A$. tene- brosa sometimes responded to desiccation with movement. Francis (1979) pointed out that aggregation, although restricting mobility, diminishes the intensity of desiccation. Hart \& Crowe's (1977) results do not falsify the hypothesis that aggregated clones are more resistant to desiccation than are isolated individuals.

Sand movement across intertidal beaches is a periodic event in southern California (Taylor \& Littler 1982, Stewart 1983) and Baja California (J. P. pers. obs.). In summer, sand buries rocks at higher levels but is washed seaward by winter storms (Hedgpeth 1957, Stewart 1983). The clonal form can withstand sand burial (Littler et al. 1983) for up to 3 mo (Taylor \& Littler 1982), a common and predictable disturbance in some intertidal areas of California (Taylor \& Littler 1982, Stewart 1983). Solitary anemones may also live semiburied in sand (Hand 1955). It is likely that, while buried, the anemones are at a disadvantage with respect to non-burial conditions because, for example, feeding may be difficult.

\section{Hypothesis}

We tested the hypothesis that Anthopleura elegantissima with different degrees of aggregation (aggregated vs 'wandering' and solitary anemones) and of unequal size (small vs large solitary anemones) would show dissimilar behavioral responses to certain types of disturbance and that differing degrees of aggregation and sizes have characteristic susceptibilities to disturbance. These dissimilar behaviors would help the anemones to avoid different types of disturbance. This hypothesis implicitly states that differences in mobility and size can partially explain the distribution of a species, and the form or sizes found in a disturbed habitat; more mobile and larger anemones would be more independent of some kinds of disturbances than the less mobile and smaller anemones

In the face of desiccation, organisms with greater surface/volume ratio would be more susceptible, and as a consequence, might increase their mobility. Therefore, following increased desiccation one would expect a larger increase in mobility by small solitaries and wandering anemones than by large solitaries and aggregated clonal anemones. Sand burial would be more severe for small anemones than for large ones because they are less able to elongate the column bringing the oral disc above the sand. Again, mobility was expected to be more important for small anemones in avoiding sand burial.

For the clonal form, we tested whether the aggregative behavior that helps prevent desiccation is disadvantageous in avoiding sand burial because it limits capacity of movement. In this case, the solitary form 
would be more apt to avoid sand burial by mobility than the clonal form

\section{METHODS}

Experimental work was performed between fall 1985 and spring 1986. Anemones Anthopleura elegantissima were collected from rocky shores 4,8 and $30 \mathrm{~km}$ north of Ensenada, on the Pacific Coast of Baja California, Mexico. The anemones were grouped into 4 categories: (1) aggregated clonal anemones, (2) wandering clonal anemones, (3) small solitary anemones and (4) large solitary anemones. Sizes of anemone categories ( $\overline{\mathrm{x}} \pm \mathrm{SD} \mathrm{mm}$; relaxed column diameter) were (1) $8.8 \pm 2.0$, (2) $8.5 \pm 1.7$. (3) $8.9 \pm 2.0$ and (4) $30.8 \pm 4.9$ in the desiccation experiments and (1) $9.8 \pm$ 1.6, (2) $9.8 \pm 1.5$, (3) $9.7 \pm 1.8$ and (4) $30.2 \pm 4.2$ in the sand burial experiments.

Small solitary anemones were distinguished from the clonal form by isolated occurrence and by the color of the oral disc. The oral disc in small solitaries is grass green, sometimes very slightly marked, while in the clonal form it is dark olive green. The color of the oral discs of the small solitaries matched that of large solitaries. Another less consistent characteristic was the color of the column; it was always creamy in solitaries but generally more dark green in the clonal form. Wandering anemones were usually found in holes where it was difficult to remove them undamaged. For the experiments, therefore, most of the wandering clones were individuals separated from aggregations, one per clone. Thus, we worked with 'detached modules'. A critial assumption in this work is that the wandering anemones so obtained do not differ from natural wandering anemones in susceptibility or behavioral response to the experimental disturbances.

Experimental procedures. The anemones were kept in aquaria with biologically filtered (Spotte 1974) seawater for 10 to $16 \mathrm{~d}$ until experiments were initiated. Except where noted, each anemone was fed once with a portion of mussel 11 to $15 \mathrm{~h}$ before the beginning of the experiment. Experiments were performed in a constant temperature room $\left(18^{\circ} \mathrm{C}\right)$ with a pair of $75 \mathrm{~W}$ fluorescent tubes $45 \mathrm{~cm}$ over the trays and a photoperiod of $13 \mathrm{~L}: 11 \mathrm{D}$. During the experiments, anemones were kept in still water at $18^{\circ} \mathrm{C}$. Table 1 summarizes the 20 treatments ( 4 anemone categories under each of 5 conditions).

Desiccation: survival. The variable measured was survival; these anemones were not fed prior to experimentation. Twenty anemones of each category ( 2 clonal aggregations with 10 anemones each) were placed in dry, slightly convex plastic dishes, which were randomly positioned on a table. After $48 \mathrm{~h}$, survival was measured by identifying live anemones as those which reacted to a mechanical stimulus and had a glossy appearance. To maintain a dry substratum and to eliminate variability in the quantity of liquid exuded by different anemones, this liquid was removed as necessary by blotting, being careful to avoid disturbing the anemones.

Desiccation: behavior. There was large variability in the quantity of material adhering to the anemone's columns; to standarize the effect of hot air (see below), all particles were manually removed $4 \mathrm{~d}$ before the initiation of experiments. Anemones were placed in experimental plastic trays $(41 \times 30 \times 13 \mathrm{~cm}$; base marked with $1 \times 1 \mathrm{~cm}$ squares) and only those that were attached to the substrate were used. The anemones were subjected to 2 conditions:

Condition $I$ : slight desiccation. Anemones were exposed to air at room temperature for $3 \mathrm{~h}$ on each of 10 successive days.

Condition II: strong desiccation. As in Condition I, but every 30 min hot air was blown from a hair dryer across the trays for $4 \frac{1 / 2}{2} \mathrm{~min}$ during which the temperature of the air at the bottom of the tray was 30 to $35^{\circ} \mathrm{C}$ (6 applications each day; $15 \%$ of total exposure).

Water exuded by the anemones during exposure to air was removed occasionally in both conditions by blotting. The experimental trays were refilled with freshly filtered seawater after each exposure. Movement was recorded as the linear distance between the

Table 1. Summary and designation of experimental treatments. Each combination of 1 condition and 1 anemone category constituted 1 treatment

\begin{tabular}{|c|c|c|c|c|c|}
\hline \multirow{3}{*}{$\begin{array}{l}\text { Anemone } \\
\text { category }\end{array}$} & \multicolumn{3}{|c|}{ Desiccation } & \multicolumn{2}{|c|}{ Sand burial behavior } \\
\hline & \multirow[t]{2}{*}{ Susceptibility } & \multicolumn{2}{|c|}{ Behavior } & \multirow{2}{*}{$\begin{array}{c}\text { Sand } \\
\text { addition }\end{array}$} & \multirow[t]{2}{*}{ Control } \\
\hline & & Slight des. & Strong des. & & \\
\hline Aggregated clonal & T1 & T5 & $\mathrm{T} 9$ & T13 & T17 \\
\hline Wandering clonal & $\mathrm{T} 2$ & T6 & $\mathrm{T} 10$ & T14 & T18 \\
\hline Small solitaries & T3 & T7 & $\mathrm{T} 11$ & T15 & T19 \\
\hline Large solitaries & $\mathrm{T} 4$ & $\mathrm{~T} 8$ & $\mathrm{~T} 12$ & T16 & $\mathrm{T} 20$ \\
\hline
\end{tabular}


positions of the pedal disk center at the beginning of the experiment and then at $12 \mathrm{~h}$ intervals. Experiments were divided as follows: (1) For aggregated and wandering clonal, and for small solitary anemones, each experimental unit included 22 to 24 anemones (3 aggregations of 7 to 8 anemones each). Six simultaneous treatments were replicated 3 times within $42 \mathrm{~d}$ (Table 1; each replication or 'block' included T5, T6, T7, T9, T10 and T11). (2) For large solitary anemones each experimental unit included 4 or 5 anemones (Table 1; T8 and T12; 4 simultaneous replications per treatment).

Sand burial: behavior. The anemones were placed in translucent plastic containers $(15.5 \times 12.5 \times 19 \mathrm{~cm})$ with the pedal disc in the angle between wall and base, so they potentially could climb up the wall. Only those anemones that were partially or fully attached to the vertical wall at the beginning of the experiments were counted. The anemones were subjected to 2 conditions:

Condition I: control. Anemones continuously immersed in water.

Condition II: sand addition. While the anemones were immersed in seawater, a $1 \mathrm{~cm}$ deep layer of sand was added to the container every $8 \mathrm{~h}$ for $4 \mathrm{~d}$ (final accumulation $=12 \mathrm{~cm}$ ). Successful escape from sand burial was measured at the end of the experiment as the proportion (see below) of anemones per experimental unit with their oral discs above the sand while still attached to the substrate.

Experiments were divided as follows: (1) For clonal aggregated, clonal wandering, and small solitary anemones an experimental unit included 7 equidistant or 7 contiguous-in-line (clonal aggregations) anemones. There were 9 replicates in the sand addition condition and 3 in the control (Table 1: T13, T14, T15 and T17, T18, T19); all were performed synchronously. (2) For large solitary anemones an experimental unit consisted of a single anemone. There were 25 replicates in the sand addition condition and 16 in the control (Table 1: T16 and T20).

Data analyses. The raw data from the experiments on behavioral response to desiccation were skewed to the left. Therefore they were transformed using $\log (x+1)$ to satisfy the assumptions of ANOVA. (Sokal \& Rohlf 1979). The mean of all the transformed measures in each experimental unit (each tray) was used in the statistical analyses. The data for the clonal aggregated, clonal wandering and small solitary anemones of 3 blocks ( 1 block $=$ one synchronous performance of all these treatments) were clumped and a 2-way ANOVA. $(2 \times 3)$ was performed (Treatments T5, T6, T7, T9, T10, T11; Table 1). A 2-way analysis was used because the error due to blocking was generally low. A priori comparisons generated by the hypothesis were performed with the Least Significant Difference ('LSD') method
(Sokal \& Rohlf 1979). A 1-way ANOVA was performed with the large solitary anemones (strong vs slight desiccation; T8, T12; Table 1). For the proportion data (aggregated, wandering and small solitary anemones in the 'sand addition' condition) a Kruskal-Wallis test, corrected for ties with a posteriori simultaneous test procedures, was performed (STP, which uses the Us statistic; Sokal \& Rohlf 1979). No statistical analysis was performed with the control condition nor with data from the large solitary anemones.

\section{RESULTS}

\section{Desiccation experiments}

All of the initial 20 aggregated clonal and 20 large solitary anemones survived after $48 \mathrm{~h}$ of exposure, but only 4 wandering clonal anemones and 4 small solitary anemones survived desiccation. Fig. 1 shows the total movement for each category of anemones under both

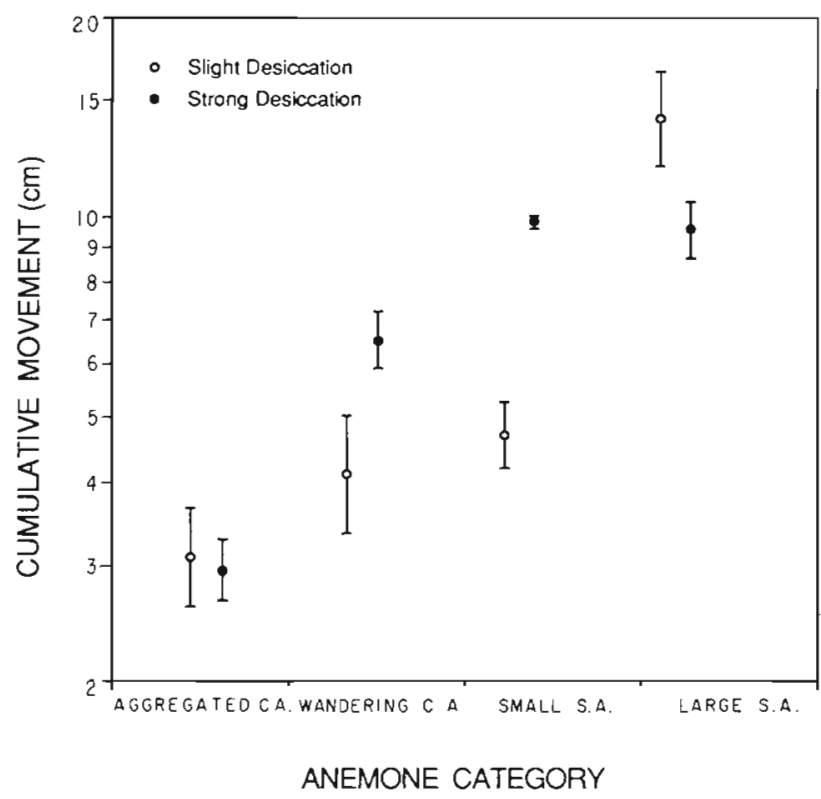

Fig. 1. Anthopleura elegantissima. Anemone movement under slight and strong desiccation. Data transformed as $\log (x-1)$. Mean and \pm 1 standard error $N=3$ except in the large solitaries where $N=4$. C. A.: clonal anemones; S. A.. solitary anemones

desiccation conditions. Aggregated anemones did not differ in their responses. Wandering and small solitary anemones moved further with strong desiccation, with differences between the 2 treatments greater for the small solitaries. Large solitary anemones moved less in the strong desiccation condition.

Comparisons of data for clonal and small solitary anemones (2-way ANOVA; Table 2 ) shows evidence of 
Table 2. Anthopleura elegantissima. Results of experiments on behavior in desiccation for clonal and small solitary anemones. Two-way ANOVA ( $p<0.05 ; \cdots p<0.01 ; \cdots p<0.001)$ See text for results of a priori tests

\begin{tabular}{|lrccc|}
\hline Source of variation & df & SS & MS & F-value \\
\hline Desiccation conditions & 1 & 0.1274 & 0.1274 & $12.74 \cdots$ \\
Anemone category & 2 & 0.3921 & 0.1960 & $19.60 \cdots$ \\
Des. con $\times$ Ane. cat. & 2 & 0.0895 & 0.0447 & 4.47 \\
Error & 12 & 0.1202 & 0.0100 & \\
Total & 17 & 0.791 & & \\
\hline
\end{tabular}

significant differences in movement between desiccation conditions $(p<0.01)$ and between anemone category $(p<0.001)$. The anemone category $x$ desiccation condition interaction was also significant $(p<0.05)$. The a priori multiple comparisons test (LSD value $=$ $0.1779,95 \%$ confidence) indicated significant differences in the strong desiccation condition between aggregated vs wandering clones and wandering vs small solitary anemones. Contrasting slight desiccation vs strong desiccation resulted in significant differences between wandering and small solitary anemones, but aggregated clones did not differ. No evidence of significant differences was found between large solitary anemones $\left(F_{1.6}=4.01 ; p>0.05\right)$

\section{Sand burial experiments}

Fig. 2 shows the proportions of each category that successfully escaped burial or that became detached or buried. Clonal aggregated and wandering anemones were similar in behavior. Most were buried and very few escaped. Fewer small solitaries were buried $(30.9 \%)$ than were aggregated $(63.7 \%)$ or wandering $(67.1 \%)$ clones, and more small solitaries $(33.2 \%)$

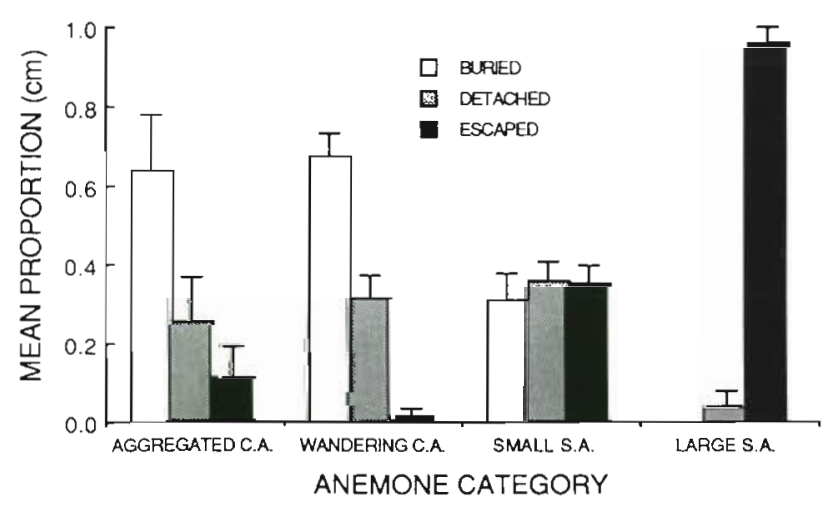

Figg. 2. Anthopleura elegantissima. Anemones that successfully escaped sand disturbance and that failed. Mean +1 standard error. $N=9$ except in the large solitaries where $N=$ 25. C.A.: clonal anemones; S.A.: solitary anemones avoided the disturbance compared with aggregated $(11.1 \%)$ or wandering $(1.6 \%)$ clones. Of large solitaries, $96 \%$ escaped burial, $4 \%$ detached and none were buried.

There was evidence for significant differences (Kruskal-Wallis test; $H=14.74 ; p<0.001$ ) in the proportion of aggregated, wandering and small solitary anemones that successfully escaped the disturbance. The Us a posteriori non-parametric multiple comparisons test ( $U_{S}=67.0$ at $95 \%$ confidence) showed evidence that small solitary anemones avoided the disturbance with different frequency than the aggregated or wandering clones, but no evidence of difference was found between these 2 latter groups.

In the control treatment none of the wandering or aggregated clones climbed up the minimum distance to avoid a potential sand disturbance and few solitaries did (the 'minimum distance' was taken from the sand addition experiments). The proportion of small solitary anemones that climbed upwards in the sand addition condition was higher than in the control conditions (33.2 vs $6.0 \%$ ). The proportion of large solitary anemones that climbed up in the sand addition condition $(37.5 \%)$ was similar to the control condition $(35.7 \%)$. Climbing response was irrelevant for large solitaries because they maintained their oral surface above the sand by column elongation.

\section{DISCUSSION}

\section{Desiccation}

Aggregated and wandering clonal anemones

The experiments on susceptibility to desiccation corroborate work by Roberts (1941) and Hart \& Crowe (1977), and Francis' (1979) suggestion that the aggregated configuration is less susceptible to desiccation than wandering anemones, by providing a lower surface/volume ratio. Likewise, our results support the prediction that wandering but not aggregated anemones would move more under severe desiccation conditions. By increasing movement under harsh conditions wandering anemones increase their chance of finding better conditions. For aggregated clones the aggregation represents a refuge; for them, too much movement may lead to disaggregation.

Three mechanisms may explain the lower mobility in the aggregates compared with the wandering individuals: (1) the effect of hot air is reduced in the aggregation, due to the lower surface exposed and therefore lower desiccation stress per individual in an aggregation, than for a wandering one; (2) the 'physical constraints of being aggregated' restrict the lateral move- 
ments of all but peripheral anemones; (3) physical contact among the members of an aggregation may inhibit movement independently of other mechanisms ('intrinsic aggregation effect'). Mechanisms 1 and 2 were diminished in effect by the small number of individuals per aggregation ( 7 or 8 ). Mechanism 2 should be unimportant to aggregation maintenance in the early stages of an aggregation, i.e. when there are only a few modules. Mechanism 1 may be very important under natural conditions, but it does not appear to be the only reason for aggregating, since Taylor \& Littler (1982) reported a subtidal aggregation, where desiccation does not occur. Aggression between genotypes (Francis 1973b) may also maintain natural aggregations. Aggregations consist of modules of the same genotype: a disaggregating module may be forced to retreat if it encounters other genotypes.

Large and small solitary anemones

The experiments on susceptibility to desiccation corroborate the prediction that small anemones are more susceptible to desiccation than are large ones. Similar results were obtained by Ottaway \& Thomas (1971) and Ottaway $(1973,1979)$ for Actinia tenebrosa.

Our results did not refute the prediction that small solitaries would react more actively to desiccation than large anemones. Although both groups moved similarly under the strong desiccation condition, only small solitaries had higher mobility in the strong than in the slight desiccation condition. Therefore, small anemones reacted to desiccation by increasing their movement, but large ones did not. The high mobility found in the solitary form is not fully explained by desiccation, since large solitaries had high mobility under both conditions, and in fact, appeared to move more in the slight desiccation condition than in the strong desiccation condition.

\section{Sand burial}

Aggregated and wandering clonal anemones

In the behavior experiments, there were no differences in evasion to sand burial between aggregated and wandering clonal anemones. The differences in configuration seem of little importance for the avoidance of this disturbance. However, the experiment imposed an artifact for the aggregated anemones, since they were placed directly adjacent to each another in the experimental tray. This disposition tested the 'intrinsic aggregation effect' (by being in contact) but not the 'physical constraints of being aggregated' and implied that no anemone would obstruct another in its way up. This contrasts to natural situations, where aggregations rarely occur in rows ( $\mathrm{J}$. P. pers. obs.). If the aggregated anemones were more naturally aggregated one would expect to obtain even lower rates of escape.

Large and small solitary anemones

The prediction that small solitary anemones would react to sand disturbance more actively than large ones was corroborated by the finding that more small anemones climbed upwards in the sand addition treatment than in control trays, but this difference did not occur in large anemones. Large solitary anemones avoided the sand disturbance at high rates (96\%), but this was a consequence of their large size and not of their reactive movement, because the proportions that climbed upwards in both the sand addition and the control conditions were very similar (ca 1/3). Small solitaries showed moderately low rates of evasion $(33.2 \%)$, and any small solitary that escaped the disturbance also climbed upwards.

For small solitary anemones the best strategy for escaping sand disturbance seems the same as for desiccation: high mobility and high rates of growth would operate together to reduce the effects of either disturbance.

\section{Clonal and solitary anemones}

Clonal and solitary anemones co-occur in diverse habitats. Where clones predominate, the solitary anemones are frequently found in depressions that contain pebbles, cobbles and sand (Francis 1979, J. P pers. obs.). In some habitats with unstable substrate and occasionally innundated by sand, solitary anemones are more numerous than wandering and aggregated clonal anemones; aggregations occur mostly on large boulders (J. P. pers. obs.).

In the desiccation experiments, small solitaries moved more than wandering anemones and both groups moved more than aggregated clones. We propose that wandering anemones move less than the solitary forms because they tend to aggregate. Since the strategy of the aggregated clones would involve little movement and the aggregated configuration is more successful in their usual habitats (Sebens 1983), it is inferred that the wandering anemones share this restriction, an 'intrinsic aggregation effect' imposed by the dominant strategy. However, the clonal form needs to retain some capacity for movement, an important mechanism of secondary habitat selection in the sexually produced recruits (Sebens 1982). 
The solitary forms do not aggregate, and they do not reproduce asexually (Francis 1979). Their potential large size makes them more resistant to desiccation. With distinct strategies to avoid desiccation, neither the aggregated clones nor large solitary anemones moved more with higher desiccation. Conversely, both the small solitary and the wandering anemones increased their movement. In both clonal and solitary forms time would generate a less susceptible state by producing more aggregations and/or larger sizes. However, the strategy of aggregating restricts movement.

Solitary anemones avoided the sand disturbance better than the clonal form by consequence of their large final size or by higher mobility. For the clonal anemones, restrictions in size (Sebens 1979) and mobility are both consequences of the aggregated way of life. Large size and higher mobility seem also important to avoid other disturbances than sand burial. In changing habitats mobility would be very important, and, for example, large aggregates do not form in areas without stable substrate.

It would seem that the low mobility which is a consequence of the aggregated strategy would reduce the effects of desiccation, but this would be at the expense of the alternative strategy of high mobility which helps to avoid other disturbances. Aggregation does not preclude movement but the anemones of an aggregation that move would eventually not be aggregated. In the sand burial experiments, escape was always accompanied by lateral movement of individuals and loss of the aggregation. In natural habitats, the disaggregated wandering anemones are at a disadvantage with respect to the established aggregations (Sebens 1983) by susceptibility to desiccation (Hart \& Crowe 1977) as well as by aggressive interaction (Francis 1973b).

Although the clonal form may be less adapted to escape sand disturbance, its demonstrated resistance to burial may be very important: Taylor \& Littler (1982) found that the clones were able to resist their superior competitor, the reef building polychaete Phragmatopoma californica, by compensatory mortality of the worm, via sand and desiccation disturbances. Thus, in sand-influenced intertidal habitats, the disturbance (sand innundation) that is presumably stressing the anemones (at the physiological level) is also helping them to persist (at the community level).

The results of this study suggest that disturbance caused, or is causing, evolutionary divergence. Disturbance events could be powerful agents of natural selection. Desiccation and other disturbances (including sand deposition) may affect differential reproductive success of different configurations, sizes and species. For dealing with desiccation, 2 strategies seem adequate: (1) aggregation (implying low mobility) and (2) high mobility in the case of the isolated forms. As high and low mobility represent the end of a continuum, this may be a case of disruptive selection. A simple model of speciation has been proposed elsewhere (Pineda 1986).

It would be premature to conclude that disturbances have caused or are causing evolutionary divergence; there are other factors to consider (Waters 1973, Francis 1979, Sebens 1979). In particular Sebens (1979) proposed a model that predicts that the 3 forms of organization in anthozoid polyps (including aggregated and solitary forms) are primarily related to prey size.

In this work it has been shown that disturbances could influence the size and configuration of the polyps. It is proposed that the differences in size and mobility associated with different disturbances are likewise important, and that these differences can partially explain and predict the numerical predominance and success of configurations, sizes and forms in habitats influenced by different disturbances.

Acknowledgements. Jorge Casián and many friends in Ensenada helped us with friendship and good faith during the practical stages of this study. A. Carvacho and A. Velázques reviewed the thesis manuscript, and $S$. Hurlbert advised on experimental design. We further acknowledge the important critical advice of P. K. Dayton on the thesis proposal. Many people helped us to improve the manuscript: Joan Stewart particularly with the English and Jim Barry, Paul Dayton, Tim Ragen, Joan Stewart and 2 anonymous reviewers with valuable criticisms. Erika del Castillo helped at every stage of the work with moral and practical support. Without her, this study would not even have been conceived. This article is based on a dissertation submitted in partial fulfiliment of the requirments for the M.S. degree by J. P. to the Centro de Investigación Científica y de Educación Superior de Ensenada, México, and was supported by the people of México through the Consejo Nacional de Ciencia y Tecnología, with a fellowship to J. P. and research grants to A. E.

\section{LITERATURE CITED}

Annett, C., Pierotti, R. (1984). Foraging behaviour and prey selection of the leather seastar Dermasterias imbricata. Mar. Ecol. Prog. Ser. 14: 197-206

Carefoot, T. (1977). Pacific seashores. A guide to intertidal ecology. University of Washington Press, Seattle

Connell, J. H. (1978). Diversity in tropical rain forests and coral reefs. Science 199: 1302-1310

Dayton, P. K. (1971). Competition, disturbance and community organization: the provision and subsequent utilization of space in a rocky intertidal community. Ecol. Monogr. 41 351-388

Denny, M. W., Daniel, T L., Koehl, M. A. R. (1985). Mechanical limits to size in wave-swept organisms. Ecol. Monogr 55: 69-102

Dethier, M. N. (1984). Disturbance and recovery in intertidal pools: maintenance of mosaic patterns. Ecol. Monogr. 54 99-118

Francis, L. (1973a). Clone specific segregation in the sea anemone Anthopleura elegantissima. Biol. Bull. mar. biol Lab., Woods Hole 144: 64-72 
Francis, L. (1973b). Intraspecific aggression and its effect on the distribution of Anthopleura elegantissima and some related anemones. Biol. Bull. mar. biol. Lab., Woods Hole 144: 73-92

Francis, L. (1979). Contrast between solitary and clonal lifestyles in the sea anemone Anthopleura elegantissima. Am Zool. 19: 669-681

Hand, C. (1955). The sea anemones of central California. Part II. The endomyarian and mesomyarian anemones. Wasmann J. Biol. 13: 37-99

Hart, C. H., Crowe, J. H. (1977). The effect of attached gravel on the survival of intertidal anemones. Trans. Am. Microsc. Soc. 96: 29-41

Hedgpeth, J. W. (1957). Sandy beaches. In: Hedgpeth, J. W (ed.) Treatise of marine ecology and paleoecology. Vol 1. Ecology Mem. no. 67. Geol. Soc. of America, Colorado, p. $587-608$

Jackson, J. B. C. (1977). Competition on marine hard substrata: the adaptive significance of solitary and colonial strategies. Am. Nat. 111: 743-767

Littler, M. M., Martz, D. R., Littler, D. S. (1983). Effects of recurrent sand deposition on rocky intertidal organisms: importance of substrate heterogeneity in a fluctuating environment. Mar. Ecol. Prog. Ser. 11: 129-139

Ottaway, J. R. (1973). Some effects of temperature, desiccation, and light on the intertidal anemone Actinia tenebrosa Farquhar (Cnidaria: Anthozoa). Aust. J. mar. Freshwat. Res. 24: 103-126

Ottaway, J. R. (1978). Population ecology of the intertidal anemone Actinia tenebrosa. I. Pedal locomotion and intraspecific aggression. Aust. J. mar Freshwat. Res. 29: $787-802$

Ottaway, J. R. (1979). Population ecology of the intertidal anemone Actinia tenebrosa. III. Dynamics and environmental factors. Aust. J. mar Freshwat. Res. 30: 41-62

Ottaway, J. R., Thomas, I. M. (1971), Movement and zonation of the intertidal anemone Actinia tenebrosa Farqu. (Cnidaria: Anthozoa) under experimental conditions. Aust. J. mar Freshwat. Res. 22: 63-78

Paine, R. T. (1979). Disaster, catastrophe and local persistence of the sea palm Postelsia palmaeformis. Science 205: 685-687

Paine, R. T., Levin, S. A. (1981). Intertidal landscapes: disturbance and the dynamics of pattern. Ecol. Monogr 51 $145-178$

Pineda, A. J. (1986). Efecto selectivo del disturbio en poblacianes de anémonas de la Bahía de Todos Santos, Baja California, México. Thesis, Centro de Investigación Cien-

This article was presented by Professor N. D. Holland, La Jolla, California, USA túfica y de Educación Superior de Ensenada. Ensenada, Baja California, México

Roberts, B. J. (1941). A survey of the methods employed by intertidal organisms in resisting desiccation. M. A. thesis. Stanford University, Stanford

Sebens, K. P. (1979). The energetics of asexual reproduction and colony formation in benthic marine invertebrates. Am Zool. 19: 683-697

Sebens, K. P. (1980). The regulation of asexual reproduction and indeterminate body size in the sea anemone Anthopleura elegantissima (Brandt). Biol. Bull. mar. biol. Lab. Wood Hole 158: 370-382

Sebens, K. P. (1982). Recruitment and habitat selection in the intertidal sea anemones, Anthopleura elegantissima (Brandt) and A. xanthogrammica (Brandt). J. exp. mar. Biol. Ecol. 59: 103-124

Sebens, K. P. (1983). Population dynamics and habitat suitability of the intertidal sea anemones Anthopleura elegantissima and Anthopleura xanthogrammica. Ecol. Monogr. 53: $405-433$

Smith, B. L., Potts, D. C. (1987). Clonal and solitary anemones (Anthopleura) of western North America: population genetics and systematics. Mar. Biol. 94: 537-546

Sokal, R. R., Rohlf, F. J. (1979). Biometría. Blume, Madrid

Sousa, W. P. (1979). Disturbance in marine intertidal boulder fields: the nonequilibrium maintenance of species diversity. Ecology 60: 1225-1239

Sousa, W. P. (1985). Disturbance and patch dynamics on rocky intertical shores. In: Pickett, S. T. A., White, P. S. (eds.) The ecology of natural disturbance and patch dynamics. Academic Press, New York, p. 101-124

Spotte, S. (1974). Aquarium techniques: closed-system marine aquariums. In: Mariscal, R. N. (ed.) Experimental marine biology. Academic Press, New York, p. 1-19

Stewart, J. G. (1983). Fluctuations in the quantity of sediments trapped among thalli on intertidal rock platforms in southern California. J. exp. mar. Biol. Ecol. 73: 205-211

Suchanek, T. H. (1981). The role of disturbance in the evolution of life history strategies in the intertidal mussels Mytilus edulis and Mytilus californianus. Oecologia (Berl.) 50: $143-152$

Taylor, P. R., Littler, M. M. (1982). The roles of compensatory mortality, physical disturbance, and substrate retention in the development and organization of a sand-influenced, rocky-intertidal community. Ecology 63: 135-146

Waters, V L. (1973). Food preference of the nudibranch Aeolidia papillosa, and the effect of the defenses of the prey on predation. Veliger 15: 174-192

Manuscnpt first received: September 29, 1988

Revised version accepted: April 10, 1989 